\title{
Adiaspiromicose pulmonar: achado casual em paciente falecido de febre amarela
}

\author{
Pulmonary adiaspiromycosis: casual finding \\ in a patient died of yellow fever
}

\author{
Mário A.P. Moraes, Maria Iolanda Gomes e Leonora M. Souza Vianna
}

\begin{abstract}
Resumo Durante um surto de febre amarela (forma rural da infecção) instalado, em fins de 1999, no Estado de Goiás, Brasil, um enfermo, com sintomatologia suspeita, faleceu no Hospital Universitário de Brasília, DF, cinco dias após a admissão. À necropsia, microscopicamente, além das alterações hepáticas características da infecção, encontraram-se nos pulmões e linfonodos hilares, estruturas arredondadas, reconhecidas como adiaconídios de Emmonsia parva var. crescens.
\end{abstract}

Palavras-chaves: Micose pulmonar. Adiaspiromicose. Emmonsia parva var crescens. Emmonsia crescens. Chrysosporium parvum var crescens.

Abstract During an outbreak of yellow fever (rural form of the infection) ocurred recently in the State of Goiás, Brazil, a patient, with clinical manifestations suggestive of the infection, died in the University Hospital of Brasilia, DF, on the fifth day from admission. Postmortem examination revealed, microscopically, the characteristic alterations of the infection, and discovered in the lungs and hilar lymph nodes round microrganisms identified as adiaconidia of Emmonsia parva var. crescens.

Key-words: Pulmonary mycosis. Adiaspiromycosis. Emmonsia parva var crescens. Emmonsia crescens. Chrysosporium parvum var crescens.

A adiaspiromicose humana é doença fúngica de localização predominantemente pulmonar, causada pela espécie Emmonsia parva var. crescens (Emmons e Jellison) van Oorschot 1980. Os elementos da forma tecidual ou parasitária desse agente não se reproduzem no organismo do hospedeiro; limitam-se a crescer, podendo atingir 300 um ou mais de diâmetro. São chamados adiaconídios e têm origem em propágulos (conídios) produzidos pela forma saprofítica do fungo. A maneira de transmissão é desconhecida, mas os conídios, formando aerossóis, quando inalados, devido ao seu pequeno tamanho - 2 a $4 \mu \mathrm{m}$-, atravessam facilmente as barreiras do sistema respiratório e atingem os alvéolos pulmonares. Dentro dos alvéolos, não germinam nem se multiplicam; sob influência da temperatura corporal do hospedeiro, aumentam de volume e se transformam em adiaconídios. Cedo, porém, degeneram e morrem, em conseqüência da intensa reação tecidual necrótico-supurativa que eles provocam, dirigida talvez contra produtos metabólicos eliminados pelos microrganismos em crescimento. A morte dos adiaconídios é seguida pela regressão natural e completa das lesões, as quais se transformam antes em granulomas e exibem sinais de fibrose na periferia. Constituindo norma a resolução espontânea do processo, admite-se, hoje, ser a adiaspiromicose uma doença autocurável, conceito importante a ter-se em mente, quando da avaliação do efeito de drogas antifúngicas no tratamento dessa micose.

Não ocorrendo reprodução do agente no organismo do hospedeiro, a gravidade da doença depende do número de conídios inalados. Embora a reação contra eles seja individual, se as lesões forem muitas, pode haver confluência de duas ou mais, aumentando as áreas pulmonares comprometidas pela inflamação. Um inóculo maciço, único ou repetido, formado por milhões de conídios, provoca em geral inflamação tão extensa e grave ${ }^{2}$ que pode determinar a morte do paciente por insuficiência respiratória ${ }^{45}$. Inóculos menores causam manifestações clínicas moderadas ou leves, podendo a presença do fungo passar mesmo despercebida; os adiaconídios seriam então descobertos apenas por acidente ${ }^{1}$, como aconteceu no presente caso. Formas clínicas protraídas constituem o resultado de exposições múltiplas e consecutivas ao agente.

Centro de Anatomia Patolológica do Hospital Universitário de Brasília, Brasília, DF.

Endereço para correspondência: Dr. Mário A. P. Moraes. Centro de Anatomia Patológica, Hospital Universitário de Brasília, Via L2 Norte, SGAN 605, Mód. C, 70840-050 Brasília, DF.

Fax: $5561307-1588$.

Recebido para publicação em 30/5/00. 


\section{RELATO DO CASO}

Sexo masculino, 45 anos, natural do Estado do Ceará, carpinteiro, residente em Sobradinho, DF. Ao ser hospitalizado em 20 de fevereiro de 2000 , referiu febre alta e cefaléia frontal, manifestações surgidas seis dias antes. $\mathrm{Na}$ ocasião, estava trabalhando, desde o início do mês, em uma chácara próxima ao rio Maranhão, no município de Niquelândia, GO, local onde já se instalara o ciclo silvestre de transmissão do vírus da febre amarela. Dois dias após a admissão, o estado do paciente se agravou com o aparecimento de vômitos amarelados, icterícia franca, dor abdominal difusa e diarréia. Os vômitos e as fezes tornaram-se enegrecidos e foram observados sangramentos diversos. Surgiram manifestações de insuficiência renal - proteinúria, oligúria, azotemia (uréia: $174 \mathrm{mg} / \mathrm{dl}$ e creatinina: $6,18 \mathrm{mg} / \mathrm{dl}$ ) e, no dia 24 de fevereiro, foi instalada diálise peritoneal; às $23 \mathrm{~h}$ do mesmo dia, no entanto, após crises convulsivas, veio ele a falecer.

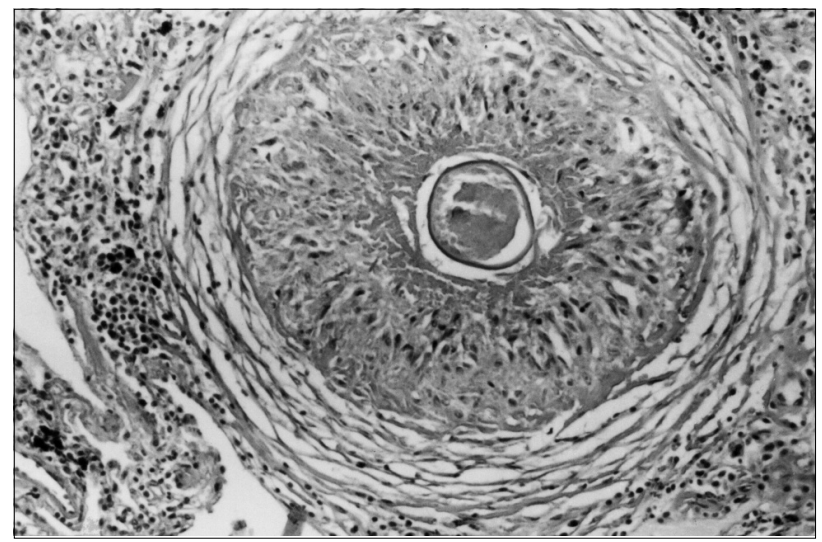

Figura 1 - Pulmão: granuloma formado por histiócitos epitelióides e contendo adiaconídio. HE. 200x.
À necropsia, além das alterações microscópicas características da febre amarela (lesão de Rocha Lima), vistas no fígado, detectou-se ainda a presença de antígeno do vírus amarílico em células hepáticas. Ao completar-se o estudo histológico do caso, pelo exame das demais vísceras, descobriram-se nos pulmões vários granulomas - 2 ou 3 por corte histológico constituídos por histiócitos epitelióides. Esses granulomas, bem delimitados por feixes concêntricos de fibras colágenas na periferia (Figura 1), exibiam, no centro, corpúsculos redondos, volumosos, de membrana espessa e PAS-positiva, identificados como adiaconídios de Emmonsia parva var crescens (Figura 2). Granulomas semelhantes, encerrando adiaconídios, intactos ou fragmentados, quase todos em regressão, foram também encontrados em linfonodos hilares (Figura 3).

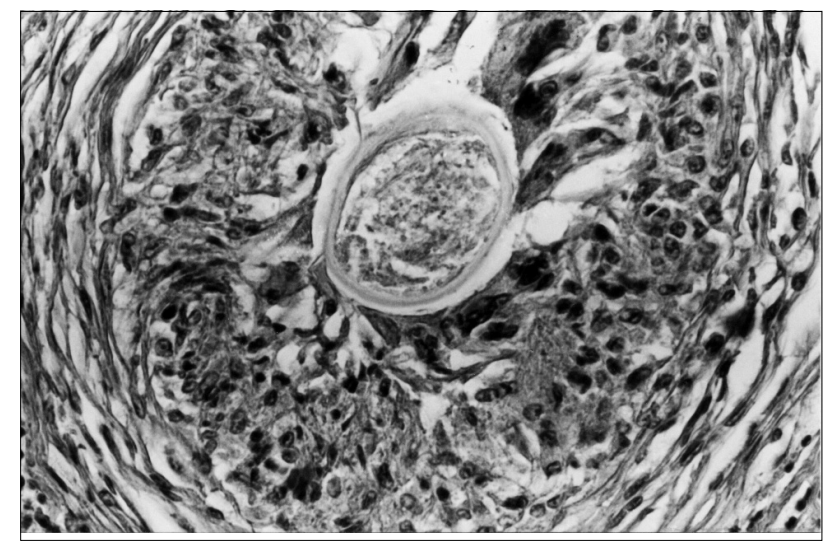

Figura 2 - Pulmão: adiaconídio no centro de granuloma, cercado por células gigantes tipo corpo estranho. HE. 400x.

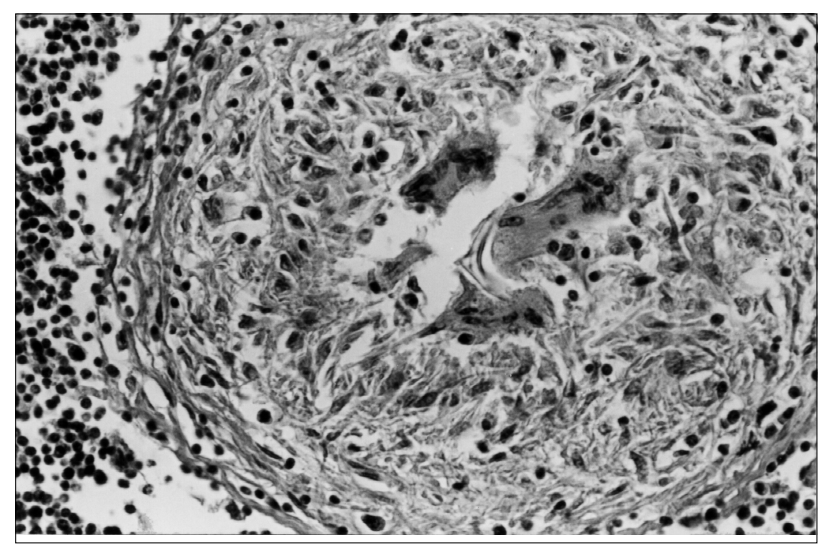

Figura 3 - Linfonodo: granuloma com restos da membrana de um adiaconídio. HE. 400x. 


\section{DISCUSSÃO}

Os casos de adiaspiromicose pulmonar referidos no Brasil - 24 ao todo, já incluído o aqui descrito - indicam a existência de uma larga faixa endêmica que se estende do sul do Piauí até o Rio Grande do Sul, compreendendo o Distrito Federal e os Estados de Goiás, Bahia, Minas Gerais, São Paulo e Paraná.

O presente caso, um achado fortuito, é o terceiro oriundo do Distrito Federal, pois o paciente residia na cidade de Sobradinho, DF, embora tivesse contraído a febre amarela no Estado de Goiás. Comparando-se o tempo de permanência do paciente - inferior a três semanas - em Niquelândia, GO, com o tempo estimado de evolução das lesões pulmonares da adiaspiromicose, já na fase final, concluiu-se que a exposição ao fungo teria ocorrido no local onde o paciente vivia, isto é, dois a três meses antes do achado necroscópico, devida talvez à profissão de carpinteiro por ele exercida ${ }^{3}$.

Por outro lado, o número pequeno de lesões e o aspecto dos adiaconídios, muitos já em colapso ou fragmentados
(Figura 3), caracterizavam uma forma de adiaspiromicose dita esparsamente disseminada, forma em geral assintomática - o paciente não referiu quaisquer manifestações respiratórias anteriores à enfermidade principal - e, no caso, certamente já em regressão. Como os granulomas pareciam estar todos na mesma fase evolutiva, concluiu-se que o inóculo deve ter sido único e restrito.

Tendo em conta o limitado comprometimento pulmonar, merece explicação, neste caso, a presença de granulomas e adiaconídios em linfonodos hilares, fato pela primeira vez referido na adiaspiromicose humana. Como havia intensa antracose, tanto nos pulmões quanto nos linfonodos, e os alvéolos estavam cheios de macrófagos contendo partículas de carvão, é provável que esses macrófagos, atraídos pelas partículas, fagocitassem também os conídios inalados, transportando-os depois para os linfonodos, onde eles se transformaram em adiaconídios.

\section{REFERÊNCIAS BIBLIOGRÁFICAS}

1. Bambirra EA, Nogueira AM. Human pulmonary granulomas caused by Chrysosporium parvum var crescens (Emmonsia crescens). American Journal of Tropical Medicine and Hygiene. 32:1184-1185, 1983

2. Kodousek R, Vortel V, Fingerland A, Vojtek V, Sery Z, Hajek V, Kucera K. Pulmonary adiaspiromycosis in man caused by Emmonsia crescens; report of a unique case. American Journal of Clinical Pathology 56:394-399, 1971.
3. Lima TS, Moraes MA, Magalhães HQ, Athaide NS. Novo caso de adiaspiromicose humana diagnosticado por biópsia transbrônquica. Jornal de Pneumologia 24:339-341, 1998.

4. Moraes MAP, Almeida MC, Raick AN. Caso fatal de adiaspiromicose pulmonar humana. Revista do Instituto de Medicina Tropical de São Paulo 31:188-194, 1989.

5. Peres LC, Figueiredo F, Peinado M, Soares FA. Fulminant disseminated pulmonary adiaspiromycosis in humans. American Journal of Tropical Medicine and Hygiene 46:146-150, 1992. 